\title{
Nasal Polyp - An Incidental Paraganglioma
}

\author{
Ruchi SRIVASTAVA', Neelam WADHWA', Shikha GUPTA², Urvashi RAZDAN ${ }^{3}$ \\ ${ }^{1}$ Department of Pathology, University College of Medical Sciences, DELHI, INDIA \\ Departments of ${ }^{2}$ Pathology and ${ }^{3}$ Otorhinolaryngology, Jag Pravesh Chandra Hospital, DELHI, INDIA
}

\begin{abstract}
The nose is an uncommon site for head and neck paraganglioma. The diagnosis is seldom established pre-operatively; its rarity, infrequent functionality and often benign biologic outcome underlie this fact. We present one such case in a 60-year-old man who presented with right nasal obstruction and episodic epistaxis. Rhinoscopy revealed a fleshy polypoid mass arising from the anterior cartilaginous nasal septum. Imaging studies excluded extra-nasal extension. The tumor was highly vascular showing numerous variable sized, mostly thin walled branching blood vessels akin to stag-horn shape simulating a vascular neoplasm. There were large areas of hyalinization. The typical tumor morphology was discernible only in focal areas. Immuno-histochemistry confirmed the diagnosis. The tumor cells expressed neuron specific enolase; S-100 stain demonstrated a vague zell-ballen pattern. Paraganglioma is a rare histologic diagnosis in nasal polypectomy specimen. We discuss the approach to exclude its morphologic mimics including vascular tumors.
\end{abstract}

Key Words: Nose, Paraganglioma, Epistaxis, Extra-adrenal, Nasal polyp

\section{INTRODUCTION}

Tumors of paraganglia arising outside the adrenal medulla are called paraganglioma (PG) (1). They may come to clinical attention due to their potentially curable symptoms associated with hyper-function. Although considered the extra-adrenal counterpart of pheochromocytoma, they differ from the latter in many aspects. The head and neck $(\mathrm{HN})$ region is the most common extra-adrenal site for these tumors, however nasal location of such tumors is rare (2-5). We share our experience with this unexpected occurrence and discuss the diagnostic approach to exclude its morphologic mimics.

\section{CASE REPORT}

A 60-year-old male presented to a tertiary care hospital in Delhi with complaints of right nasal mass of 8-10 weeks duration causing obstruction and intermittent epistaxis. There were no complaints of rhinorrhea, allergy, headache, palpitation, tinnitus or cranial nerve palsies. He had undergone an appendectomy 18 years ago. General physical examination did not reveal any abnormalities of pulse or blood pressure. Rhinoscopy revealed a fleshy, polypoid mass arising from the anterior cartilaginous nasal septum and distending the right nostril. It bled on touch during the examination. Pre-operative investigations including imaging studies were unremarkable. With a clinical diagnosis of an inflammatory nasal polyp, right nasal polypectomy was performed under general anesthesia. The

(Turk Patoloji Derg 2016, 32:196-199)

Received : 20.06.2013 Accepted : 11.09.2013 sessile polyp was excised along with an adjacent sleeve of mucoperichondrium and anterior nasal packing done for $48 \mathrm{hrs}$. His intra-operative period and post-operative course were uneventful. Subsequent radiologic investigations were unremarkable. The patient had been asymptomatic in his 18 months follow up.

The specimen consisted of a single mucosa covered polypoid soft tissue mass measuring $1.5 \times 1.0 \times 0.4 \mathrm{~cm}$. It was formalin fixed and paraffin embedded in toto. Sections revealed a highly vascular well circumscribed tumor. The vascular channels' caliber varied from small to ectatic; few were branching and stag-horn shaped. Majority of vessels were thin walled, few larger ones had thicker walls. There were large intervening areas of hyalinization especially prominent in the perivascular location (Figure 1). The cellular areas were few and showed large cells arranged in sheets and nests. The cells had abundant clear to pale eosinophilic granular cytoplasm (Figure 2). Few showed cytoplasmic vacuoles. Nuclei were centrally located and contained inconspicuous nucleoli in many cells. Mitoses were occasional; there were no areas of necrosis. The tumor was reaching up-to the overlying epithelium, which showed squamous metaplasia and focal ulceration. Although PG was suspected, definite diagnosis was deferred to immuno-histochemistry (IHC). Polygonal cells with abundant pale cytoplasm in a highly vascular hyalinized background raised other possibilities- malignant melanoma, metastatic carcinoma, PEComa, chordoma, glomus tumor and epithelioid hemangioendothelioma

Correspondence: Neelam WADHWA

Department of Pathology, University College of Medical Sciences,

University of Delhi, DELHI, INDIA

E-mail: drneelam428@yahoo.co.in Phone: +911 1122582971 
(EH). The high vascularity and hyalinization warranted exclusion of sino-nasal type hemangiopericytoma (SNTHP) and solitary fibrous tumor (SFT).

A panel of IHC comprising chromogranin A, neuron specific enolase (NSE), S-100, HMB-45, CD34, CD31, cytokeratin, epithelial membrane antigen (EMA), smooth muscle antigen (SMA) and desmin was performed using appropriate positive and negative controls. Tumor cells strongly expressed chromogranin A and NSE (Figure 3). S-100 expression was scarce and outlined the occasional sustentacular cells and zellballen pattern. CD31 and CD34 expression was limited to endothelial cells (Figure 4). Results of other immuno-stains were negative/ non-contributory. Hence the diagnosis of PG of nose was confirmed.

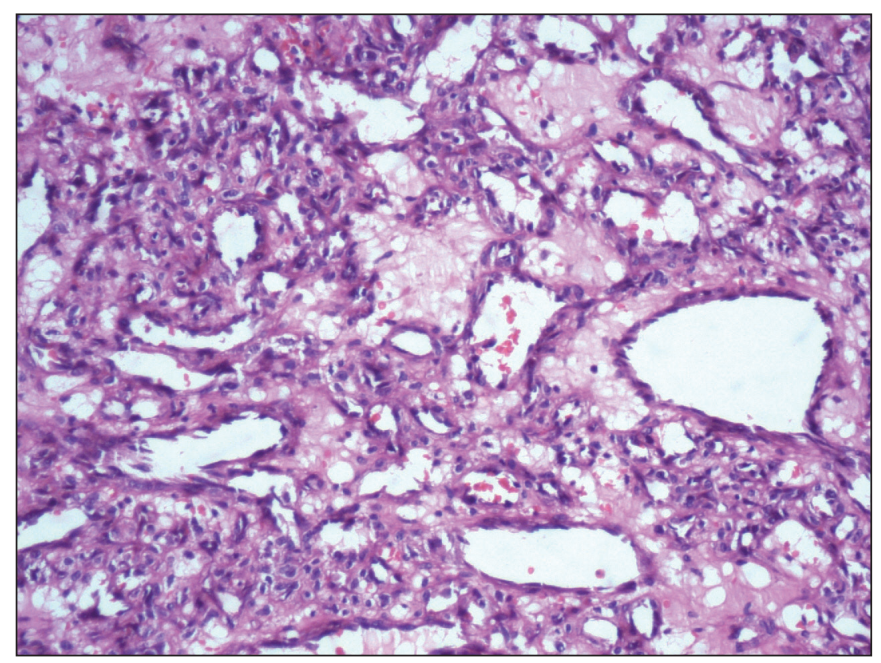

Figure 1: Numerous variably sized blood vessels with perivascular hyalinization simulating a vascular neoplasm (H\&E; x 200).

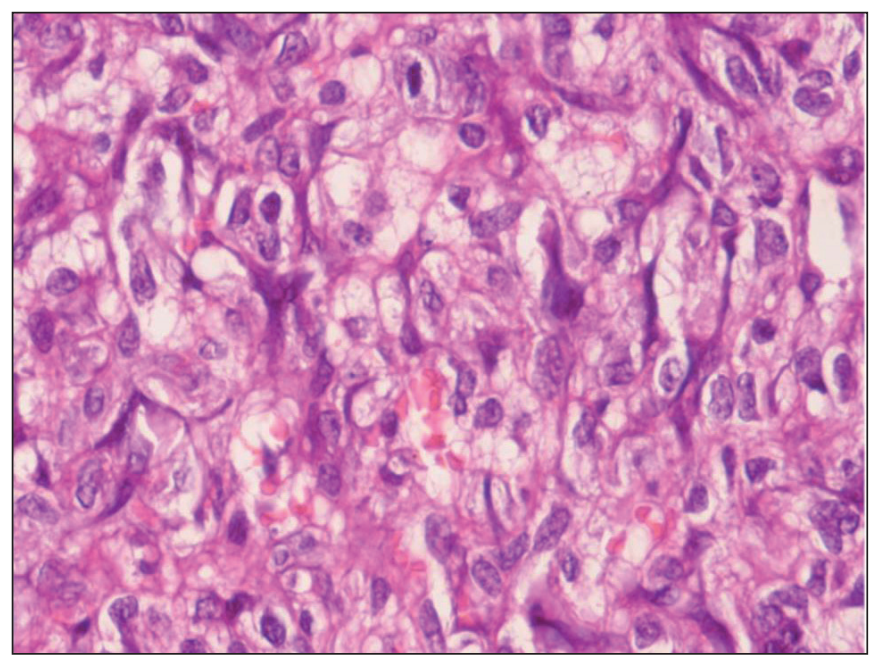

Figure 2: High magnification of the cellular area highlighting the voluminous clear to pale vacuolated cytoplasm in tumor cells (H\&E; x 400).

\section{DISCUSSION}

PGs, the neural crest origin tumors arise from paraganglia, structures lying adjacent to autonomic ganglia (1). $\mathrm{HN}$ region is the most common site of PG followed by abdominal and thoracic (2). Almost half of HN PGs are located at carotid artery bifurcation. Others in descending frequency in this region are jugulotympanic tumors and glomus vagale $(2,3)$. Rare sites of HN PG include nose, orbit, larynx and thyroid $(1,3,4)$. Almost all HN PGs are suspected pre-operatively either due to their peculiar location and/or typical imaging characteristics. Only $1.2 \%$ of HN PGs are true incidentilomas, i.e. require pathological examination of an indeterminate mass to confirm the diagnosis, as happened in our case (2).

HN PGs differ from abdominal PGs in many aspects $(2,3)$. They are associated with parasympathetic nervous system, while abdominal PGs show evidence of sympathetic activity. Despite ultra-structural evidence of neuroendocrine differentiation in HN PGs, less than $10 \%$ produce catecholamines in amounts sufficient to result in headaches, palpitations and perspiration. This is in contrast to almost one-forth of abdominal PGs patients having such symptoms. The frequency of hypertension in HN PGs (42\%) is also reported to be lower than abdominal ones (64\%) (2). Endocrine silence of HN PGs usually makes them symptomatic either as space occupying lesion related to their anatomic site or with symptoms secondary to nerve compression such as tinnitus and cranial nerve palsies $(2,3)$. HN PGs are distinctly smaller and less likely to be malignant than their abdominal counterparts $(2,5)$. In a retrospective analysis, Flines et al. did not find any

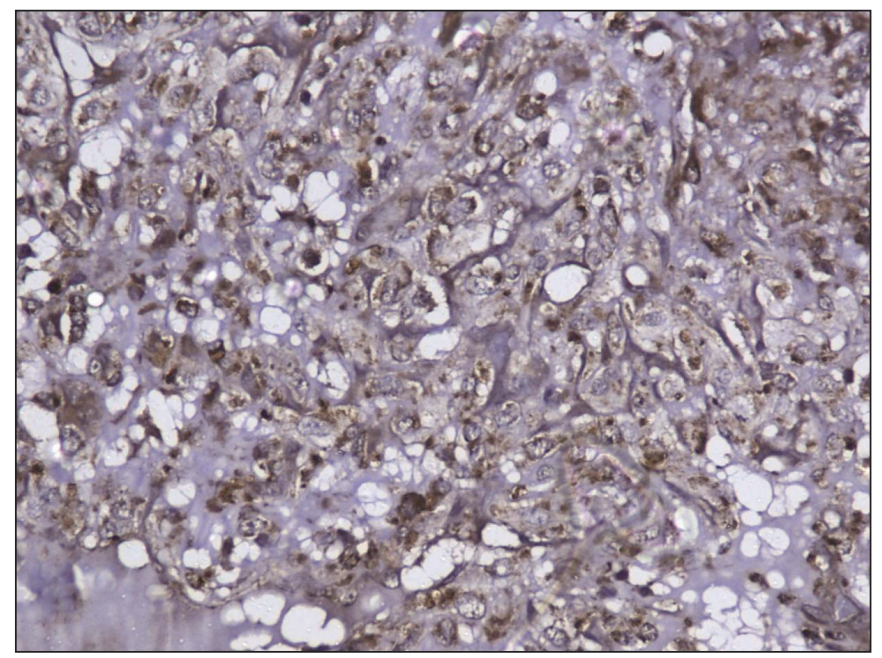

Figure 3: Diffuse and strong NSE immuno-expression in tumor cells (NSE; $\mathrm{x} 200)$. 


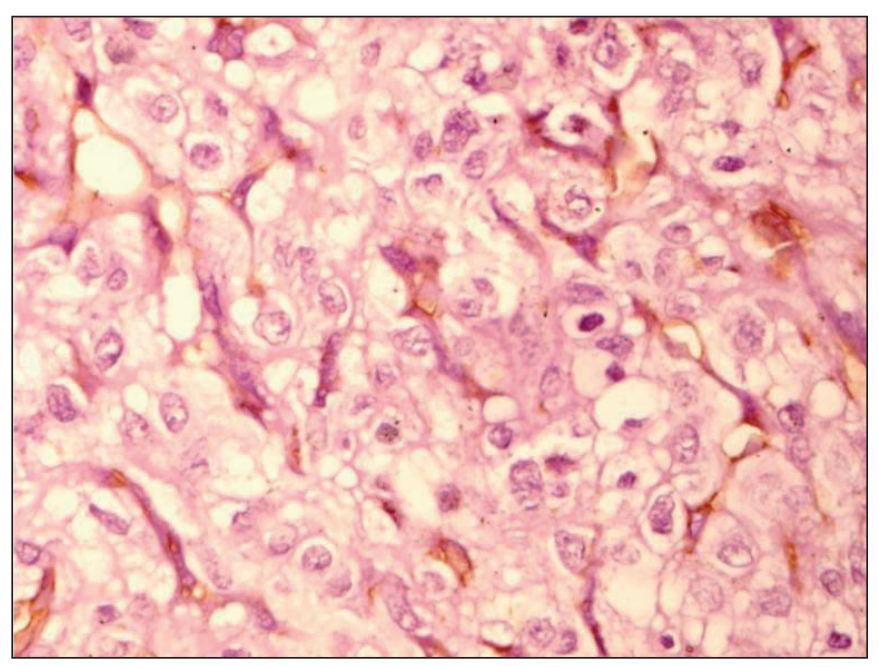

Figure 4: CD34 immuno-stain is negative in tumor cells. The endothelial cells acting as an internal control are positive (CD34; $\mathrm{x} 400)$.

difference in survival between their cohort (mean follow up $=26.4$ years) in comparison to the general population. The deaths in their study population were attributed to surgical complications of carotid body tumors (5). Up-to $30 \%$ of $\mathrm{HN}$ PGs may be associated with mutations of genes encoding various subunits of succinyl dehydrogenase (SDH) enzyme. Familial PGs are commonly multiple, bilateral and present at an earlier age than sporadic tumors. Molecular tests are indicated only in the setting of family history, previous pheochromocytoma, multiple tumors and age $<40$ years (6).

The nose is an exceptional site of PG. Till date, less than 50 nasal PGs have been described, a testimony to its rarity (1, 3-5, 7-10). Nasal PGs have been reported in a wide age range, 8-72 years $(3,7)$. They often present with nasal obstruction and/or epistaxis as happened in our case $(3,4,7)$. The highly vascular nature of the tumor and trauma attendant to its peculiar location may explain the epistaxis. It may be said that most nasal PGs are non-functional, although occasional reports of Cushing's syndrome secondary to ACTH production are on record (8). Distinction of de novo nasal PGs arising from nasal mucosa from extension of jugulo-tympanic or vagal tumors is essential to decide surgical aspects and is based on radiologic features (9). As for HN PGs, most reported nasal tumors have had a benign course, although occasional cases with late recurrence have also been reported (10).

The typical morphology of PGs composed of chief cells and surrounding sustentacular cells may not be obvious in all cases. Extensive secondary changes like hyalinization, ectatic blood vessels, sclerosis and others may render their recognition difficult as happened in our case. NSE expression is almost invariable in PGs. The sustentacular cell network is outlined by S-100 and GFAP immunostains. Demonstration of sustentacular cells may be difficult when tumor cells are present in sheets or large nests, especially in small or fragmented sections (1). Neither atypical histological features nor infiltration are considered indicative of malignancy. Metastasis to organs normally devoid of chromaffin cells remains the only evidence of malignancy $(1,10)$.

Cellular areas of PGs may resemble malignant melanoma, metastatic carcinoma, chordoma, perivascular epithelioid cell tumor (PEComa), glomus tumor and $\mathrm{EH}$, all tumors rare to the nose (11-17). They share cytologic feature of voluminous clear to eosinophilic cytoplasm of the tumor cells. Malignant melanomas usually have prominent nucleoli; they invariably show diffuse positivity for S-100 and HMB-45 (11). Appropriate clinical setting and expression of epithelial markers will help establishing diagnosis of metastatic carcinoma (12). Physalliferous cells are characteristic of chordoma, but may be few. Chordomas are decorated by cytokeratin, EMA and S-100 (13). In the present case thorough search neither revealed cells with prominent nucleoli nor with spidery cytoplasm. PGs do not stain with epithelial markers or HMB-45 and S-100 staining is limited to sustentacular cells. Radial arrangement of cells around blood vessels and low grade nuclei are seen in PEComa and glomus tumor. Although highly vascular, our case showed large areas of perivascular hyalinization rather than cellularity typical of these tumors. PEComas and glomus tumors typically stain with HMB- 45 and SMA respectively $(1,14,15)$. Expression of desmin is variable in both. PGs are typically negative for HMB-45, SMA and desmin. Conversely PEComas and glomus tumors do not express NSE. EH, an angiocentric tumor may show clusters of large cells resembling PG. Intra-cytoplasmic vacuoles often containing erythrocytes indicate its vascular origin. Endothelial cell markers like CD31 and CD34 are expressed consistently in $\mathrm{EH}(1,16)$. The cells in the present case did have vacuolated appearing cytoplasm but did not have the typical blistered look of EH; none contained erythrocytes. IHC for CD31 and CD34 outlined the endothelial cells lining the ecstatic vessels; tumor cells did not take the stain.

Highly vascular tumors with staghorn-like branching vessels and prominent hyalinization in this region, albeit rare include SNTHP and SFT $(17,18)$. SNTHP is a low to intermediate grade tumor of perivascular myoid phenotype containing HP like staghorn vessels. Its cells are bland, spindle shaped and arranged in fascicular and/or whorled pattern. Their immuno-phenotype resembles glomus 
tumor rather than HP. Most react with vimentin (98\%), SMA (92\%), and factor XIIIa (78\%); expression of CD34 is variable (17). The cells in our lesion were polygonal rather than spindle and their immuno-phenotype was typical of neuro-endocrine nature. SFT, a fibroblastic mesenchymal tumor also has prominent $\mathrm{HP}$ like branching vasculature. Its cells are generally arranged in fascicular fashion unlike the nesting pattern of polygonal cells of PGs. Its cells stain with CD34, bcl-2 and CD99 (18). CD34 stain was consistently absent in tumor cells in our case.

To conclude, we have shared our experience with an unsuspected nasal PG. This rare neoplasm of the nose is likely to be a histologic surprise in the rather common nasal polypectomy specimens. Identification of its typical morphology is essential for correct diagnosis and proper management. Immuno-staining for NSE and chromogranin A is likely to be useful in cases obscured by extensive secondary changes.

\section{REFERENCES}

1. Weiss SW, Goldblum JR. Enzinger and Weiss's Soft Tissue Tumors. 5th ed. China: Mosby Elsevier; 2008.

2. Erickson D, Kudva YC, Ebersold MJ, Thompson GB, Grant CS, van Heerden JA, Young WF Jr. Benign paragangliomas: Clinical presentation and treatment outcomes in 236 Patients. J Clin Endocrinol Metab. 2001;86:5210-6.

3. Lack EE, Cubilla AL, Woodruff JM, Farr HW. Paragangliomas of the head and neck region: A clinical study of 69 patients. Cancer 1977;39:397-409.

4. Zainine R, Sahtout S, Ouertani H, Sellami M, Beltaief N, Besbes G. Paraganglioma of the nasal cavity. Tunis Med. 2012;90:178-9.

5. de Flines J, Jansen J, Elders R, Siemers M, Vriends A, Hes F, Bayley JP, van der Mey A, Corssmit E. Normal life expectancy for paraganglioma patients: A 50-year-old cohort revisited. Skull Base. 2011;21:385-8.

6. Neumann HP, Erlic Z, Boedeker CC, Rybicki LA, Robledo M, Hermsen M, Schiavi F, Falcioni M, Kwok P, Bauters C, Lampe K, Fischer M, Edelman E, Benn DE, Robinson BG, Wiegand S, Rasp G, Stuck BA, Hoffmann MM, Sullivan M, Sevilla MA, Weiss MM, Peczkowska M, Kubaszek A, Pigny P, Ward RL, Learoyd D, Croxson M, Zabolotny D, Yaremchuk S, Draf W, Muresan M, Lorenz RR, Knipping S, Strohm M, Dyckhoff G, Matthias C, Reisch N, Preuss SF, Esser D, Walter MA, Kaftan H, Stöver T, Fottner C, Gorgulla H, Malekpour M, Zarandy MM, Schipper J, Brase C, Glien A, Kühnemund M, Koscielny S, Schwerdtfeger P, Välimäki M, Szyfter W, Finckh U, Zerres K, Cascon A, Opocher G, Ridder GJ, Januszewicz A, Suarez C, Eng C. Clinical predictors for germline mutations in head and neck paraganglioma patients: cost reduction strategy in genetic diagnostic process as fall-out. Cancer Res. 2009;69:3650-6.
7. Ketabchi S, Massi D, Santoro R, Franchi A. Paraganglioma of the nasal cavity: A case report: Eur Arch Otorhinolaryngol. 2003;260:336-40.

8. Lieberum B, Jaspers C, Münzenmaier R. ACTH-producing paraganglioma of the paranasal sinuses. HNO. 2003;51:328-31.

9. Amiraraghi N, Syed MI, Syed S, Williams AT. Paraganglioma of the skull base presenting as nasal polyps. Laryngoscope. 2013;123:577-80.

10. Sharma HS, Madhavan M, Othman NH, Muhamad M, Abdullah JM. Malignant paraganglioma of frontoethmoidal region. Auris Nasus Larynx. 1999;26:487-93.

11. Harvey RJ, DAlgorf DM. Chapter 10: Sinonasal malignancies. Am J Rhinol Allergy. 2013;1:35-8.

12. Terada T. Renal cell carcinoma metastatic to the nasal cavity. Int J Clin Exp Pathol. 2012;5:588-91.

13. Gupta N, Kaur J, Srinivasan R, Das A, Mohindra S, Rajwanshi A, Nijhawan R. Fine needle aspiration cytology in lesions of the nose, nasal cavity and paranasal sinuses. Acta Cytol. 2011;55: 135-41.

14. Bandhlish A, Leon Barnes E, Rabban JT, McHugh JB. Perivascular epithelioid cell tumors (PEComas) of the head and neck: Report of three cases and review of the literature. Head Neck Pathol. 2011;5:233-40.

15. Daugaard S, Jensen ME, Fischer S. Glomus tumours. An immunohistochemical study. APMIS 1990;98:983-90.

16. Requena L, Kutzner H. Hemangioendothelioma. Semin Diagn Pathol. 2013;30:29-44.

17. Thompson LD, Miettinen M, Wenig BM. Sinonasaltype hemangiopericytoma: A clinicopathologic and immunophenotypic analysis of 104 cases showing perivascular myoid differentiation. Am J Surg Pathol. 2003;27:737-49.

18. Vermeulen S, Ketels P, Salgado R, Creytens D, Vanderveken OM, Claes J. Solitary fibrous tumour of the nasal cavity: A case report and literature review. B-ENT. 2012;8:219-23. 